\title{
Precipitated sulfur cathode-a hybrid faradaic and pseudocapacitive discharging process
}

\author{
Agnieszka Swiderska-Mocek $^{1} \cdot$ Ewelina Rudnicka $^{1} \cdot$ Andrzej Lewandowski $^{1}$
}

Received: 17 December 2019 / Revised: 31 March 2020 / Accepted: 19 April 2020 / Published online: 30 April 2020

(C) The Author(s) 2020

\begin{abstract}
A carbon-sulfur cathode was prepared by precipitating a suspension of acetylene black and dissolved sulfur from ethanol. The morphology of the cathode material was investigated using scanning and transmission electron microscopy. The diameter of commercial sulfur particles is between 20 and $50 \mu \mathrm{m}$, while this value for the precipitated sulfur was ca. order of magnitude lower (between 2 and $5 \mu \mathrm{m}$ ). Electrochemical properties of Li|S cells were investigated by cyclic voltammetry, galvanostatic discharging, and electrochemical impedance spectroscopy. Galvanostatic discharging curves of the Li| S system may be divided into three regions. At the beginning, the discharging undergoes at an approximately constant voltage (faradaic process) to switch into a pseudocapacitive process (two discharging regions characterized by linearly decreasing voltage). The hybrid discharging faradaic-pseudocapacitive nature implies the description of the total process by two types of capacities: in coulombs (faradaic process) and in farads (pseudocapacitive regions). The calculated experimental specific energy density (free enthalpy change) during the discharging process was ca. $1063 \mathrm{Wh} \mathrm{kg}^{-1}$, approximately twofold higher in comparison with such cathodes as $\mathrm{LiFePO}_{4}$ or $\mathrm{Li}_{x} \mathrm{Mn}_{2} \mathrm{O}_{4}$. These results show that the sulfur-carbon precipitated from ethanol can serve as a promising cathode for $\mathrm{Li} \mid \mathrm{S}$ primary cells.
\end{abstract}

\section{Introduction}

The lithium-sulfur Li| S battery is a promising electrochemical system characterized by a high theoretical specific capacity of $1675 \mathrm{mAh} \mathrm{g}^{-1}$ and energy density of $2600 \mathrm{Wh} \mathrm{kg}^{-1}$ [1-3]. In addition, sulfur is an attractive material due to its large reserves and low cost. The most stable allotrope of sulfur at room temperature is cyclic octasulfur. It reacts reversibly with metallic lithium:

$\mathrm{S}_{8}+16 \mathrm{Li}^{+}+16 \mathrm{e}^{-} \rightarrow 8 \mathrm{Li}_{2} \mathrm{~S}$

Despite the many advantages of the abovementioned $\mathrm{Li} \mid \mathrm{S}$ cell, there may also be certain disadvantages. The main disadvantage of such a cathode is connected with solubility of long-chain polysulfides formed by the reduction of pure sulfur and/or by oxidation of short chain polysulfides [4]. Another problem is the insulating nature of sulfur.

Andrzej Lewandowski

andrzej.lewandowski@put.poznan.pl

1 Faculty of Chemical Technology, Poznan University of Technology, PL-60-965 Poznan, Poland
Therefore, additives are needed to increase electronic conductivity of the cathode. Modifications of the Li| S batteries are designed to improve stability of the electrode structure and the utilization of sulfur in the cathode. This may be mostly achieved by a modification of the sulfur-based composite cathode material. Sulfur-carbon composites are attractive because they improve sulfur utility as an active mass and prevent diffusion of polysulfides to the electrolyte solution. Hence, this reduces the phenomenon, which significantly limits the capacity of sulfur cathodes $[2,5]$. Such materials as mesoporous carbons [6], carbon nanotubes [7, 8], activated carbons [9], and graphene [10, 11] have been used. Ballmilling or mixing sulfur powder and carbon materials have been used in conventional sulfur electrodes [2]. Sulfur was also injected into the pores of carbon fibers [9] or deposited on multiwalled carbon nanotubes [7, 8]. A carbon cloth/ sulfur cathode also demonstrated very good electrochemical performance [12]. The original studies of the lithium-sulfur batteries have been summarized in a number of review papers. Generally, it is assumed that the discharging process is of faradaic nature. [2, 3, 5, 13-19].

The general aim of the present study was to prepare and characterize a new cathode utilizing precipitated sulfur as an active material. 


\section{Experimental}

\section{Materials}

Elemental sulfur (99.98\%, powder, Aldrich), lithium foil (0.75 mm thick, Aldrich), acetylene black (AB, Alfa Aesar), poly(vinylidene fluoride) (PVdF, Fluka), N-methyl-2pyrrolidinone (NMP, Fluka), ethyl alcohol (99.8\%, anhydrous, $\mathrm{POCh}$ ), and liquid electrolyte $1 \mathrm{M} \mathrm{LiPF}_{6}$ solution in $\mathrm{EC}+\mathrm{DMC}$ (Aldrich) were used as received. Water was purified with reverse osmosis (conductivity $<1 \mu \mathrm{S}$ ).

\section{Composite carbon/sulfur cathode and counter electrode preparation}

Saturated sulfur (2 g) suspension in ethanol (20 g) was stirred for $2 \mathrm{~h}$ at $45^{\circ} \mathrm{C}$. After sulfur sedimentation, the transparent colorless solution was decanted. Carbon material was added to the stirred sulfur solution in ethanol. The suspension of carbon material in the sulfur solution was stirred and water was slowly added, which resulted in a gray precipitate. Water + ethanol was initially evaporated at room temperature from the carbon/sulfur precipitate. The precipitate was finally dried at $40{ }^{\circ} \mathrm{C}$ for $4 \mathrm{~h}$. The sulfur content in the carbon/sulfur was monitored by weight (weight of the carbon before and after coprecipitation with sulfur). The cathode composite (AB-PS) was mixed with PVdF (10 wt \%), and the suspension in NMP was deposited on a gold counter current collector (discs with the surface area of $0.785 \mathrm{~cm}^{2}$ ). Cathodes deposited on current collectors were dried at $50{ }^{\circ} \mathrm{C}$ for $48 \mathrm{~h}$.

\section{Measurements}

Cells were assembled in a dry argon atmosphere in a glove box (MBraun, UniLabPlus). A round-shaped lithium anode (surface area of $0.785 \mathrm{~m}^{2}$, Li mass of ca. $40 \mathrm{mg}$ ) was cut off from metallic lithium foil. Electrodes were separated by a glass microfiber separator (GF/A, Whatman) soaked with the electrolyte and placed in an adapted $0.5^{\prime \prime}$ Swagelok ${ }^{\circledR}$ connecting tube. The electrochemical characteristic of cathodes was investigated using cyclic voltammetry (CV), galvanostatic discharging tests, and electrochemical impedance spectroscopy (Multichannel System Gamry, USA). Impedance spectra were obtained using a frequency response analyzer at a frequency range of $100 \mathrm{kHz}-10 \mathrm{mHz}$ at the open circuit potential and amplitude of $10 \mathrm{mV}$. After electrochemical measurements, the cells were disassembled and electrodes were washed with DMC and dried in vacuum at room temperature. X-ray diffraction of the composite cathode active material was investigated using Bruker AXS D8 apparatus. The morphology of the carbon/sulfur cathodes (pristine and after electrochemical cycling) was observed under a scanning electron microscope, SEM (Zeiss EVO 40), and TEM (Jeol JEM 1200 EXII, USA).

\section{Results and discussion}

\section{Morphology of composite cathode (XRD, TGA, SEM, and TEM)}

X-ray diffraction of the composite cathode active material (S + $\mathrm{AB}$ ) is typical of elemental sulfur due to very low intensity of carbon material (shown in Fig. 1). The deposited composite contained between 80 and $60 \mathrm{wt} . \%$ of sulfur, depending on amount of acetylene black suspended in sulfur solution in $\mathrm{C}_{2} \mathrm{H}_{5} \mathrm{OH}$. Differential thermal analysis is shown in Fig. 2, for a composite containing ca. $60 \mathrm{wt} . \%$ of sulfur indicates that the mass loss occurs between 250 and $350{ }^{\circ} \mathrm{C}$ (sulfur sublimation). Scanning electron microscopy (SEM) images of the commercial $99.98 \%$ powder and precipitated sulfur (PS) are displayed in Figs. 3 and 4, respectively. It can be seen that the diameter of commercial sulfur particles is between 20 and $50 \mu \mathrm{m}$, while this value for the precipitated sulfur is ca. one order of magnitude lower (ca. $5 \mu \mathrm{m}$ ). This effect is probably due to a relatively short time of sulfur crystals growth. On the other hand, TEM images (Fig. 5) suggest that small carbon black particles (density of ca. $80-120 \mathrm{~g} / \mathrm{L}$ ) exist in a form of agglomerates of diameter of ca. 50-100 nm.

SEM images of the acetylene black/precipitated sulfur composite cathode (AB-PS-PVdF) are displayed in Fig. 6. The mapping image of the freshly prepared cathode (Fig. $6 b)$ shows uniformly deposited carbon black particles on precipitated sulfur. As it can be observed, freshly prepared ABPS-PVdF particles are below $2 \mu \mathrm{m}$ in diameter and they resemble a flake-like morphology (Fig. 6a). However, after discharging (Fig. 6b), the cathode material based on sulfur is converted into polysulfides (AB-(LiS) $)_{x}-\mathrm{PVdF}$ with $4<x<8$ [20]) of a different morphology - small flake particle agglomerates.

\section{Cyclic voltammetry}

The electrochemical reaction mechanism of the carbon black-precipitated sulfur-PVdF (AB-PS-PVdF) cathode was more clearly revealed using cyclic voltammetry (CV). The CV scan was performed on the AB-PS-PVdF cathode between 1.2 and $2.8 \mathrm{~V}$ using $0.1 \mathrm{mV} \mathrm{s}^{-1}$ scan rate (Fig. 7). Typically, for a sulfur cathode, a three-stage redox process has been noticeably observed. In the case of the reduction process, one peak (1) was observed at a higher potential $(2.2 \mathrm{~V})$, and it may be related to the open ring reduction of cyclic $\mathrm{S}_{8}$ to the long chain lithium polysulfides, while the a pair of peaks ( 2 and 3 ) was observed at a lower potentials $(1.6-1.7 \mathrm{~V})$, which corresponds to the reduction process of polysulfides to $\mathrm{Li}_{2} \mathrm{~S}_{2}$ and $\mathrm{Li}_{2} \mathrm{~S}$. [21-23].

Generally, the potential ranges of peaks are lower than with the classic sulfur electrode. This situation is observed when 
Fig. 1 XRD spectrum of the composite cathode material (coprecipitated $\mathrm{S}+\mathrm{AB}$ )

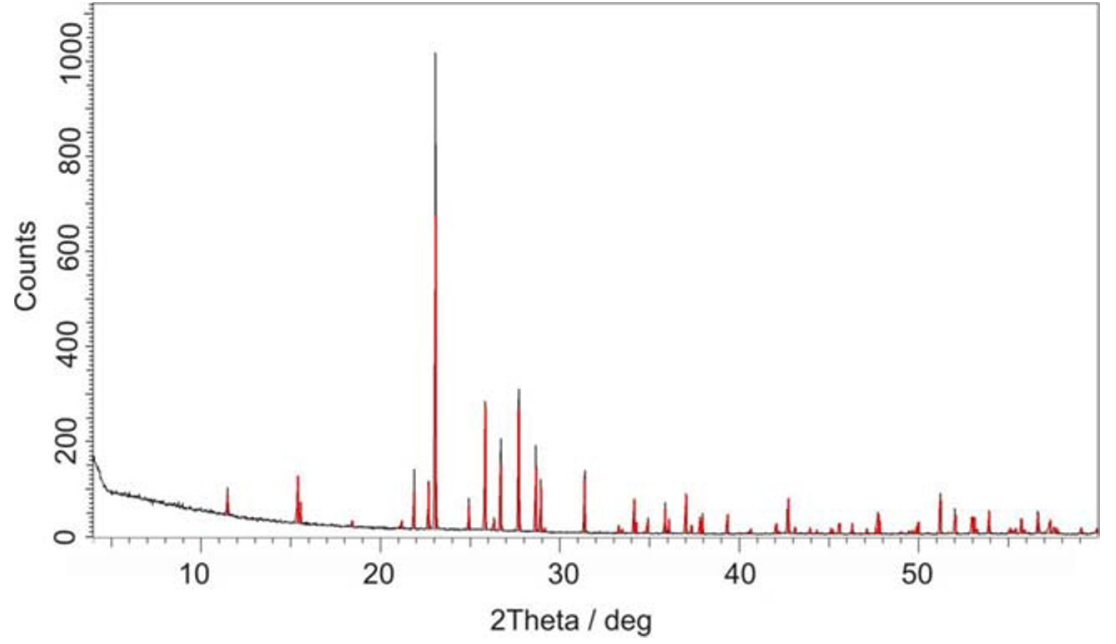

sulfur is trapped in the structure of the carbon material $[8,12]$. A reduction in the size of the peaks in subsequent cycles was observed (not shown in Fig. 7 for the sake of clarity). This is due to the lack of reversibility of the oxidation and reduction process of the sulfur electrode.

\section{Galvanostatic charging and discharging}

Figure 8 shows the voltage $(\Delta V)$ profile of the discharging process of the $\mathrm{Li} \mid \mathrm{AB}-\mathrm{PS}-\mathrm{PVdF}$ system, at a constant current of $10 \mathrm{~mA} \mathrm{~g}^{-1}$. The curve may be divided into three regions. After the system polarization, the potential drops from ca. 3.2 to ca. $2.5 \mathrm{~V}$ and then remains approximately constant (region 1) during ca. $1.2 \times 10^{5} \mathrm{~s}(33.3 \mathrm{~h})$. Due to the constant voltage, this region of the curve suggests a faradaic process of elementary sulfur ring opening and further reduction to lithium polysulfides [13] (this process may also be seen at the cyclic voltammetry curves, Fig. 7, reduction peak 1). Then the potential constantly drops (regions 2 and 3), indicating the pseudocapacitive nature of subsequent processes (which can also be seen in the voltammetry curves - peaks 2 and 3). These regions of the discharging curve (regions 2 and 3 ) reflect reduction of polysulfides [13].

\section{Capacity determination: classical approach}

Usually, galvanostatic discharging curves are plotted as the dependence of the voltage on capacity. A point of intersection of the plot with a cutoff voltage is accepted as a capacity of the system. The value of cutoff voltage, which can be found in the literature for $\mathrm{Li} \mid \mathrm{S}$ systems, varies between 1.8 and $0.8 \mathrm{~V}$ [13, $17,20,24-29]$. In the present work, the voltage drop starts at ca. $1.2 \mathrm{~V}$, which leads to the capacity value of ca. $1100 \mathrm{Wh} \mathrm{kg}^{-1}$. However, it is difficult to calculate energy (work) delivered during discharging process due to voltage changes. In addition, charging of the discharged cathode led to very low capacity values (of ca. $100-150 \mathrm{Wh} \mathrm{kg}^{-1}$ ) indicating their practical irreversibility.
Fig. 2 TGA curve of the composite cathode material (coprecipitated $\mathrm{S}+\mathrm{AB}$ )

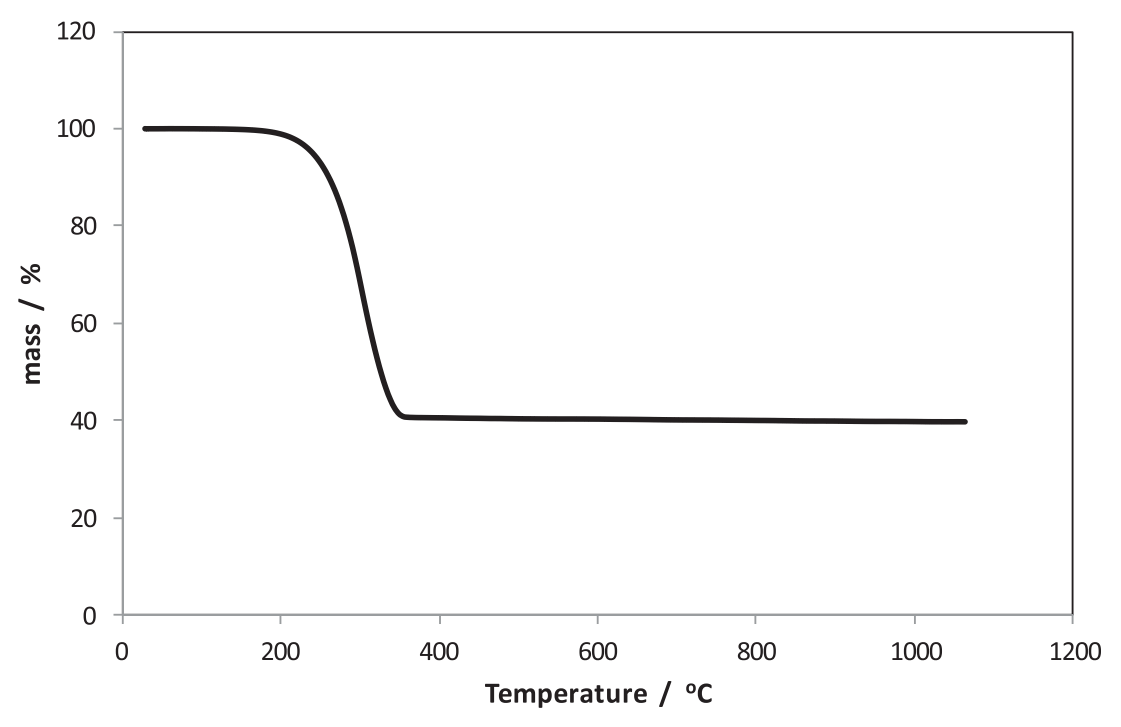



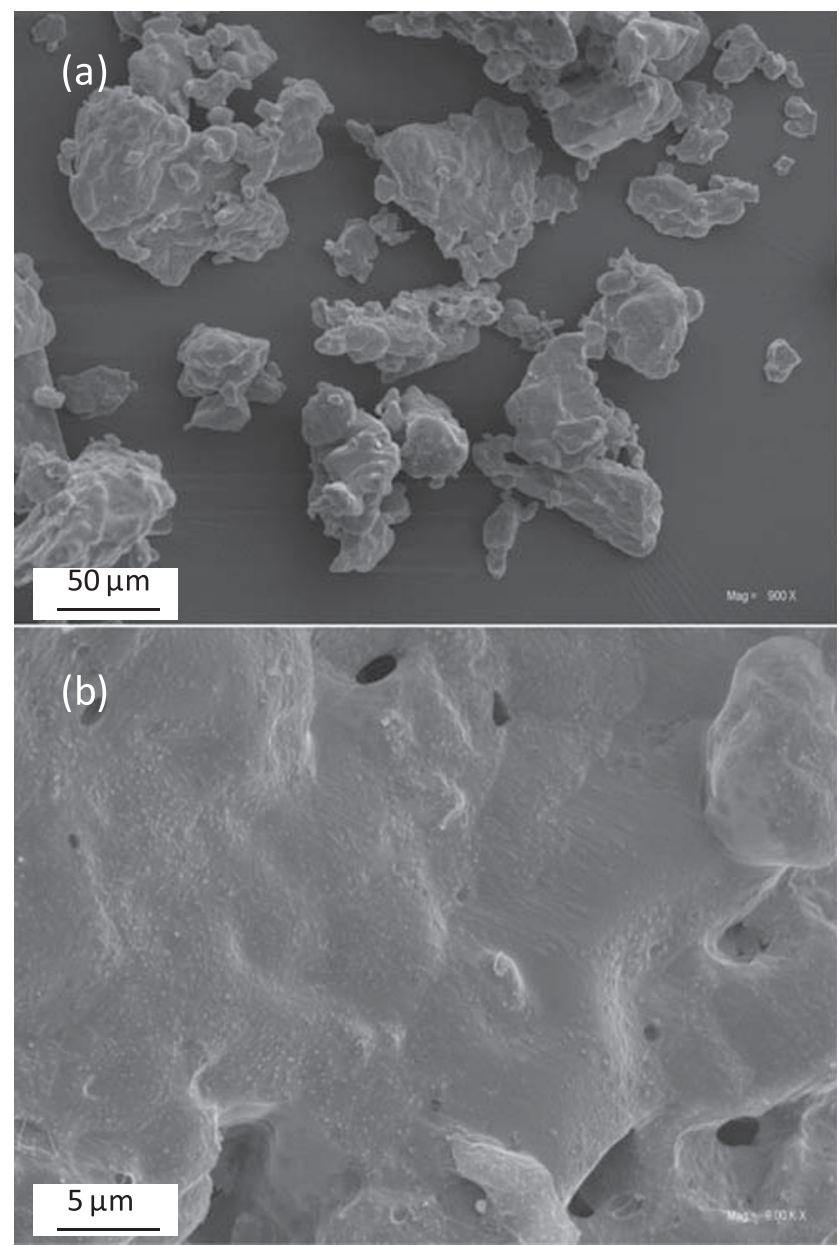

Fig. 3 Scanning electron microscopy (SEM) images of the commercial 99.98\% powder sulfur taken at two magnifications: a $900 \mathrm{x}$ and b $9 \mathrm{kx}$

\section{Delivered energy determination-hybrid faradaic/pseudocapacitive approach}

Capacity $q$ of the faradaic, process which takes place in region 1 , may be approximated by the product of constant current $I$ and time $t$ :

$q_{1}=I \times t$

Hence, according to Fig. 5: $q_{1}=10 \mathrm{~mA} \mathrm{~g}^{-1} \times 33.3 \mathrm{~h}=$ $330 \mathrm{mAh} \mathrm{g}^{-1}=1188 \mathrm{C} \mathrm{g}^{-1}$.

The capacity of the system in the pseudocapacitive regions cannot be expressed in coulombs (or Ah) but rather in farads and calculated from the equation valid for capacitors, taking into account the slope of discharging curves $\mathrm{d} V_{\mathrm{i}} / \mathrm{d} t$ :

$C_{i}=I\left(\frac{d V_{i}}{d t}\right)^{-1}$

The slope of the curve in region 2 is $7.44 \times 10^{-6} \mathrm{~V} \mathrm{~s}^{-1}$ with voltage difference of $\Delta V=2.5 \mathrm{~V}-1.6 \mathrm{~V}=0.9 \mathrm{~V}$, while in region

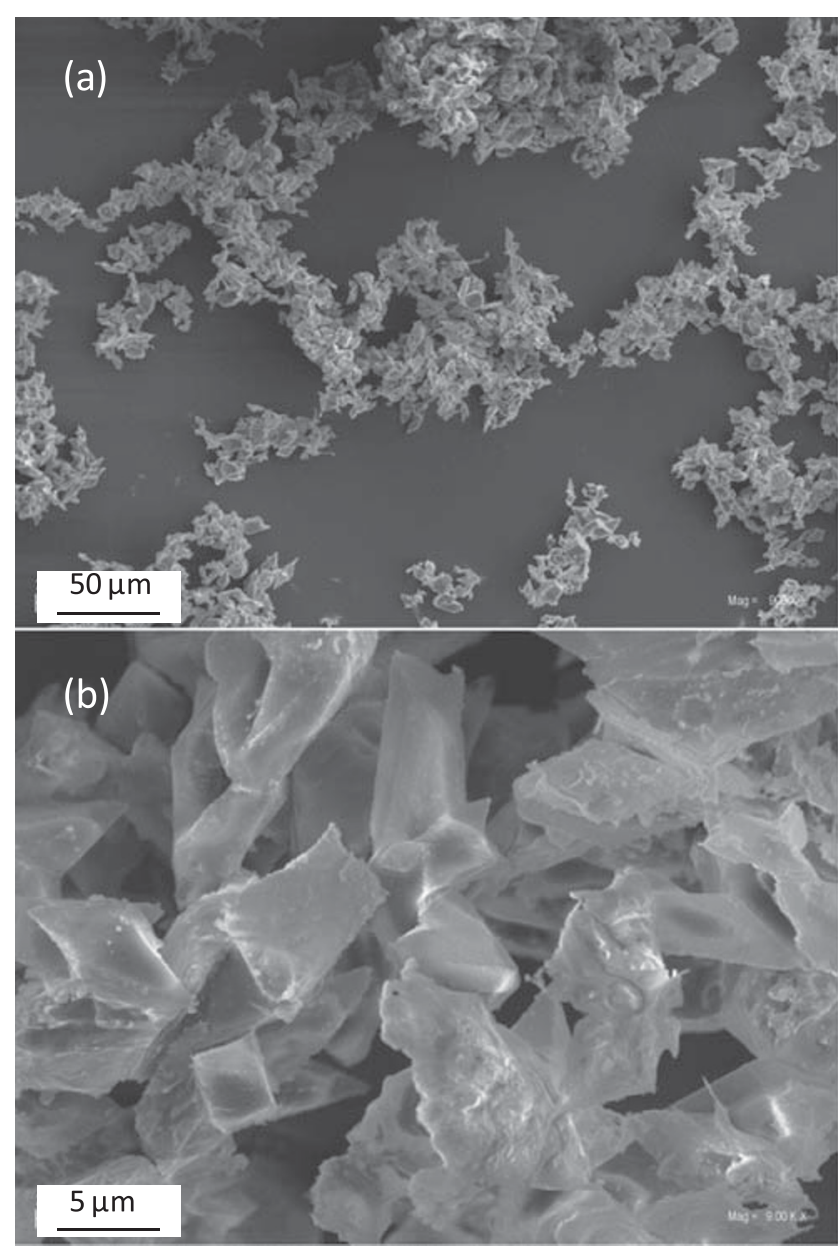

Fig. 4 Scanning electron microscopy (SEM) images of the precipitated sulfur taken at two magnifications: a $900 \mathrm{x}$ and $\mathbf{b} 9 \mathrm{kx}$

$3, \mathrm{~d} V / \mathrm{d} t=2.54 \times 10^{-6} \mathrm{~V} \mathrm{~s}^{-1}$ with $\Delta V=1.6 \mathrm{~V}-1.2 \mathrm{~V}=0.4 \mathrm{~V}$. This leads to specific capacities $C_{2}=1344 \mathrm{~F}$ and $C_{3}=3937 \mathrm{~F}$. However, a capacitance comparison of Li-ion systems working at constant or linearly changing voltage is impossible. Instead, the energy $\Delta E$ delivered (electric work $W_{\mathrm{el}}$ done by the system during discharging or free enthalpy change) in regions 1-3 can be calculated as $\Delta E=W_{\mathrm{el}}=\Sigma W_{\mathrm{i}}$. The faradaic process in region 1 leads to the following energy (free enthalpy) change:

$\Delta E_{1}=q_{1} \Delta V$

while in pseudocapacitive regions 2 and 3 , it is described by the following equation (adopted from the classical capacitors theory):

$\Delta E_{i}=\frac{1}{2} C_{i} \Delta V^{2}$

The energy change in regions 1,2 , and 3 is $\Delta E_{1}=$ $1188 \mathrm{C} \mathrm{g}^{-1} \times 2.5 \mathrm{~V}=2970 \mathrm{~J} \mathrm{~g}^{-1}, \Delta E_{2}=\left(1344 \mathrm{~F} \mathrm{~g}^{-1} \times 0.9^{2} \mathrm{~V}^{2}\right) /$ $2=544 \mathrm{Jg}^{-1}$, and $\Delta E_{3}=\left(3937 \mathrm{~F} \mathrm{~g}^{-1} \times 0.4^{2} \mathrm{~V}^{2}\right) / 2=314 \mathrm{~J} \mathrm{~g}^{-1}$, 

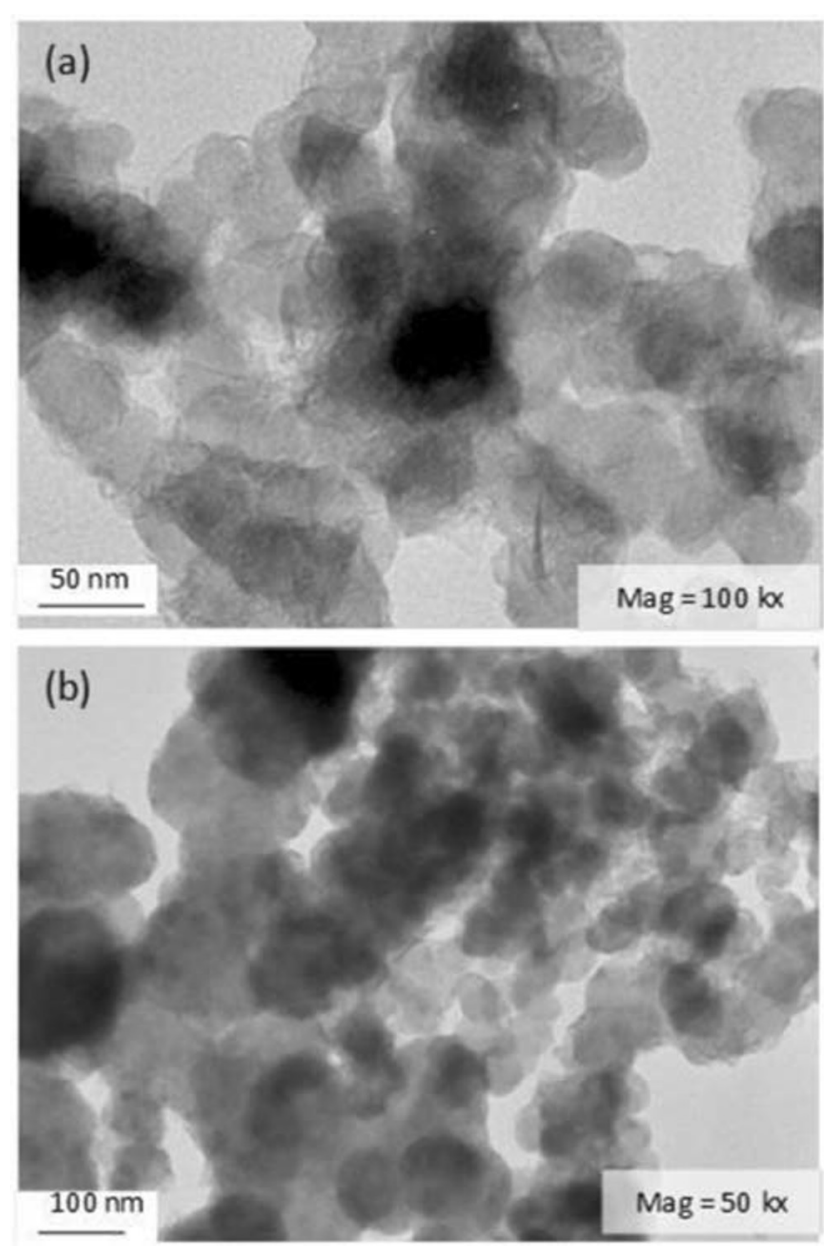

Fig. 5 Transmission electron microscopy (TEM) images of the coprecipitated sulfur and acetylene black taken at two magnifications: a $100 \mathrm{x}$ and b $50 \mathrm{kx}$

respectively. Consequently, the electric work done by the system during the discharging process equals a value of $W=$ $3828 \mathrm{~J} \mathrm{~g}^{-1}=1063 \mathrm{Wh} \mathrm{kg}^{-1}$. This value is ca. twofold higher in comparison with the corresponding values characteristic of such cathode materials as $\mathrm{LiFePO}_{4}\left(q=170 \mathrm{mAh} \mathrm{g}^{-1}, \Delta V=3.5 \mathrm{~V}\right.$, and $\left.\Delta E=2142 \mathrm{~J} \mathrm{~g}^{-1}\right)$ or $\mathrm{Li}_{x} \mathrm{Mn}_{2} \mathrm{O}_{4}\left(q=150 \mathrm{mAh} \mathrm{g}^{-1}, \Delta V=3.6 \mathrm{~V}\right.$, and $\Delta E=1944 \mathrm{~J} \mathrm{~g}^{-1}$ ). However, theoretical energy density calculated according to the reduction of elemental sulfur to lithium sulfide is as high as $9360 \mathrm{~J} \mathrm{~g}^{-1}$ (2600 $\mathrm{kWh} \mathrm{kg}^{-1}$ [13]). Much lower energy density observed in experimental systems is mainly due to dissolution of lithium polysulfides and their possible diffusion to lithium anode $[12,13]$. On the other hand, energy density of cathode based on commercial sulfur was only $1140 \mathrm{~J} \mathrm{~g}^{-1}$ (calculated according to Eq. (5)).

\section{Impedance spectroscopy (EIS)}

Figure 9 shows the impedance spectrum of a pristine sulfur electrode after its assembling ( $\mathrm{Li} \mid \mathrm{S}$ cell) and after discharging. It can be seen that both curves consist of a
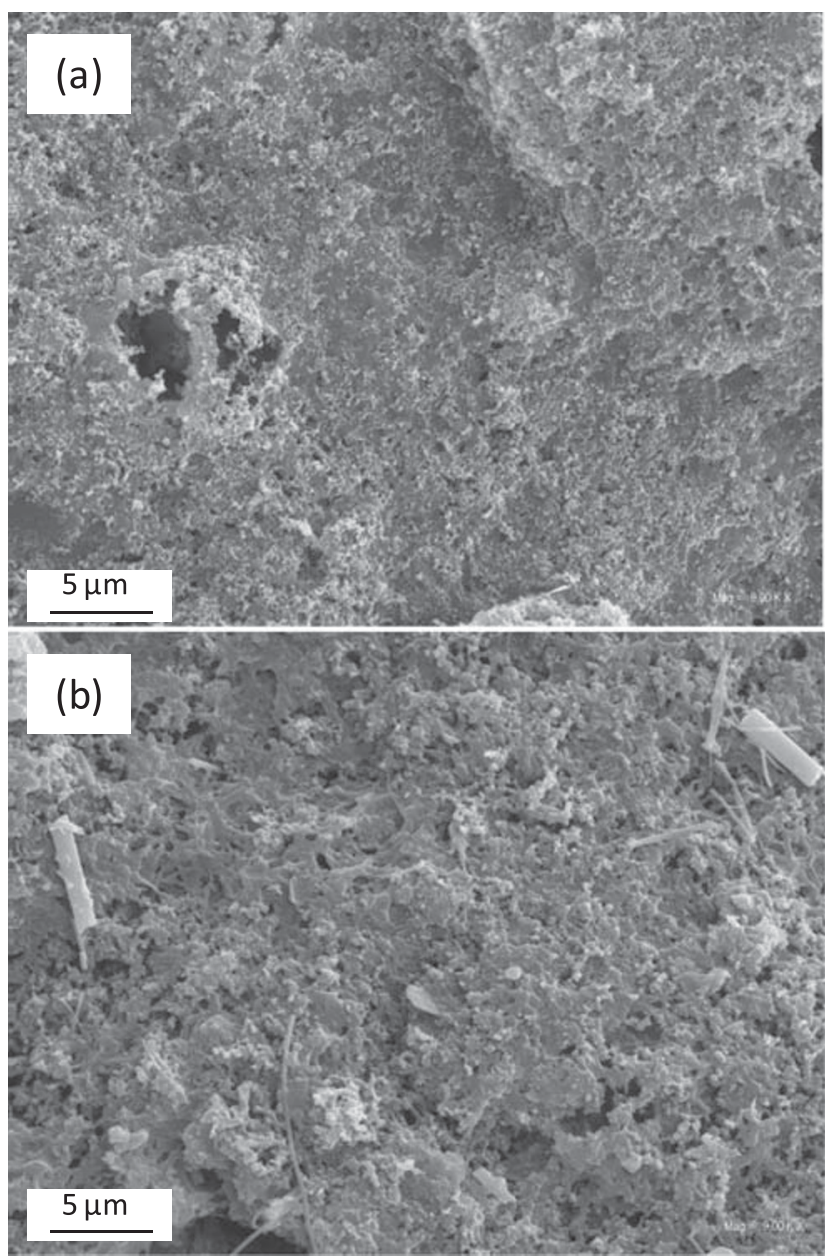

Fig. 6 SEM images of the acetylene black-precipitated sulfur-PVdF (AB-PS-PVdF) cathode: a freshly prepared; $\mathbf{b}$ after discharging

semicircle and a straight line at lower frequencies. EIS curves were deconvoluted according to the Randles equivalent circuit, consisting of series resistance $R_{\mathrm{s}}$, charge transfer resistance $R_{\mathrm{ct}}$ (in series), and a constant phase element $C P E$ in parallel to $R_{\mathrm{ct}}$ and the Warburg diffusion element. The ohmic resistance of the fresh cathode was $3.7 \Omega$, while after discharging, it increased to a comparable value of ca. $4.0 \Omega$. This indicates that the system series resistance is low and stable (with the geometric surface area of the cathode below of $1 \mathrm{~cm}^{2}$ ). The charge transfer resistance of the $\mathrm{Li} \mid \mathrm{S}$ system was ca. $100 \Omega$, while after discharging $\left(\mathrm{Li} \mid \mathrm{Li}_{2} \mathrm{~S}\right)$ somewhat higher: $178 \Omega$.

\section{Conclusions}

These results show that sulfur-carbon precipitated from ethanol can serve as a promising cathode for $\mathrm{Li} \mid \mathrm{S}$ primary cells. The diameter of commercial sulfur particles is between 20 and $50 \mu \mathrm{m}$, while this value for the precipitated sulfur is ca. one 
Fig. 7 Cyclic voltammogram of the acetylene black-precipitated sulfur-PVdF (AB-PS-PVdF) electrode vs. $\mathrm{Li} / \mathrm{Li}^{+}$. Scan rate: $0.1 \mathrm{mV} \mathrm{s}^{-1}$

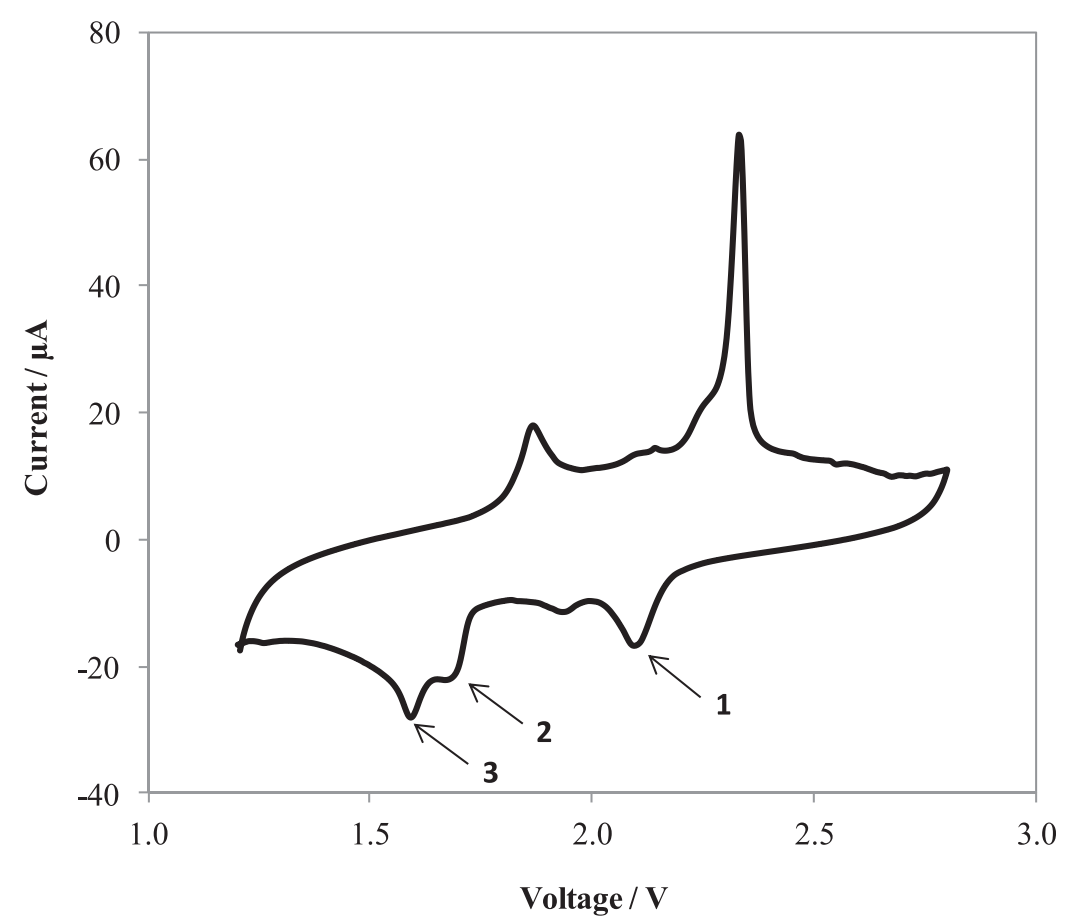

order of magnitude lower (between ca. 2 and $5 \mu \mathrm{m}$ ). Galvanostatic discharging curves of the Li| S system may be divided into three regions. At the beginning, the discharging undergoes at an approximately constant voltage (faradaic process) to switch into a pseudocapacitive process (two discharging regions characterized by linearly decreasing

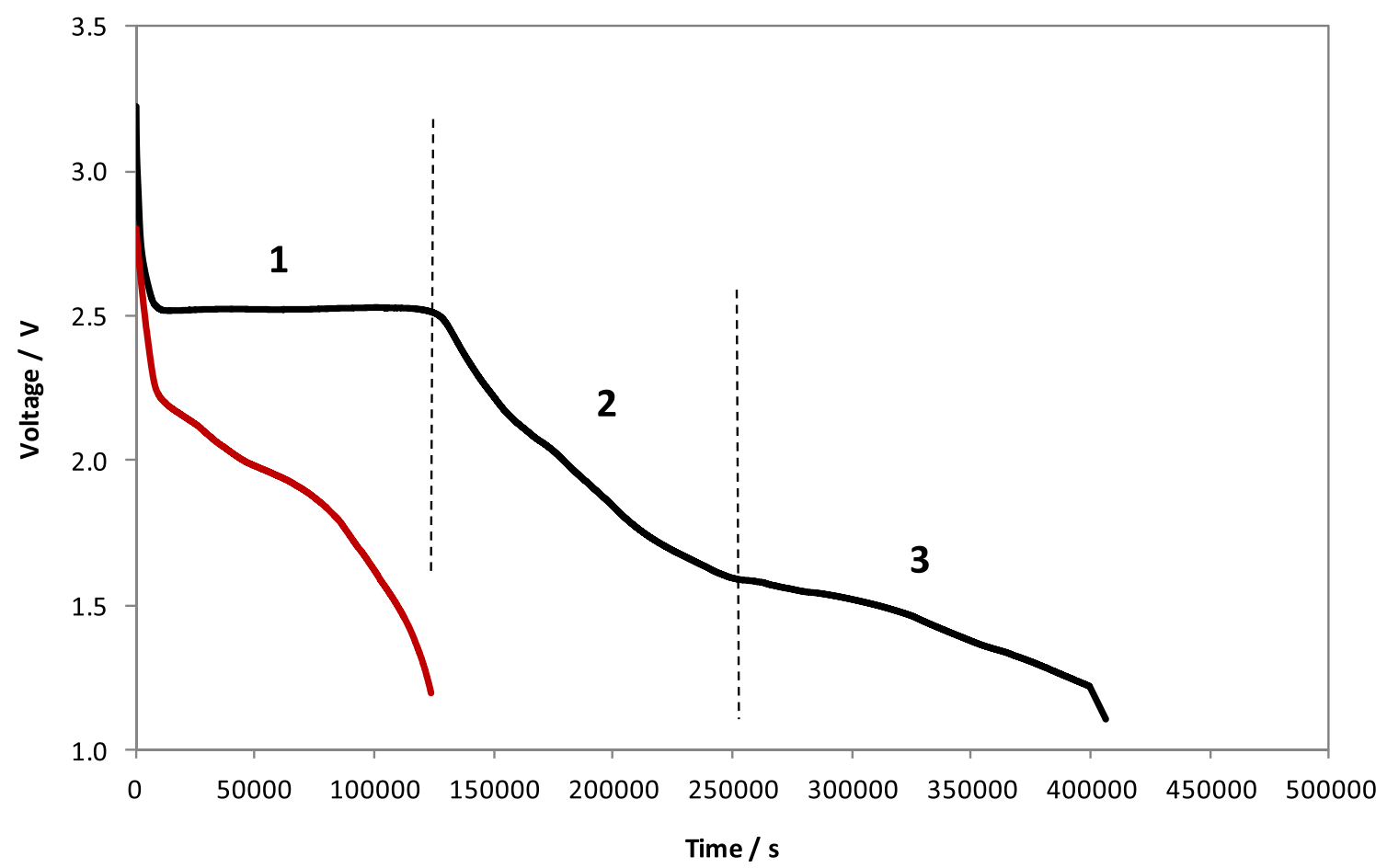

Fig. 8 Galvanostatic discharging profile of the acetylene black-precipitated sulfur-PVdF (AB-PS-PVdF) electrode (black line) and the acetylene blackcommercial sulfur-PVdF (AB-S-PVdF) electrode (red line). Current density: $10 \mathrm{~mA} \mathrm{~g}^{-1}$, counter electrode: metallic lithium 
Fig. 9 Electrochemical impedance spectroscopy of the acetylene black-precipitated sulfur-PVdF (AB-PS-PVdF) cathode before and after discharging. Counter electrode: metallic lithium. Solid lines indicate fitted curves

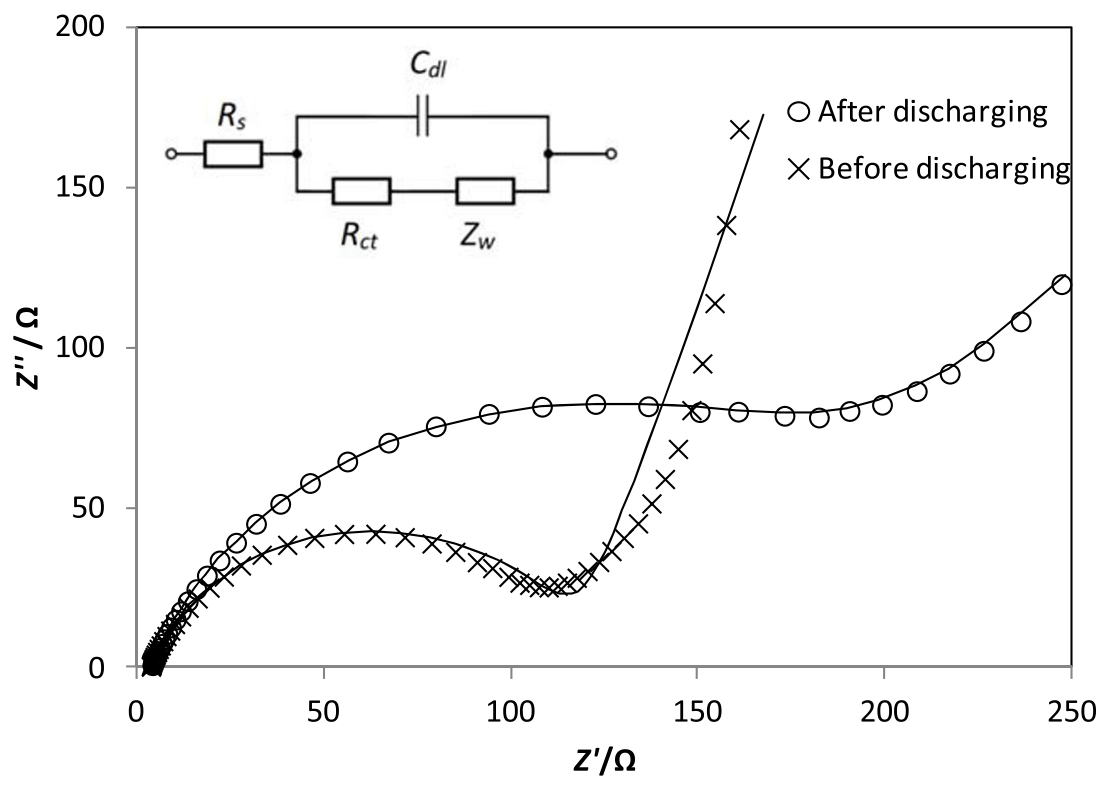

voltage). The hybrid discharging faradaic-pseudocapacitive nature implies the description of the total process by two types of capacities: in coulombs (faradaic) and in farads (pseudocapacitive regions). The calculated specific energy density (free enthalpy change) during the discharging process) was $1063 \mathrm{Wh} \mathrm{kg}^{-1}\left(3800 \mathrm{~J} \mathrm{~g}^{-1}\right)$.

Funding information This work was supported by the Polish Ministry of Science and Higher Education, grant 03/31/ 0377.

Open Access This article is licensed under a Creative Commons Attribution 4.0 International License, which permits use, sharing, adaptation, distribution and reproduction in any medium or format, as long as you give appropriate credit to the original author(s) and the source, provide a link to the Creative Commons licence, and indicate if changes were made. The images or other third party material in this article are included in the article's Creative Commons licence, unless indicated otherwise in a credit line to the material. If material is not included in the article's Creative Commons licence and your intended use is not permitted by statutory regulation or exceeds the permitted use, you will need to obtain permission directly from the copyright holder. To view a copy of this licence, visit http://creativecommons.org/licenses/by/4.0/.

\section{References}

1. Peled E, Gorenshtein A, Segal M, Sternberg Y (1989) Rechargeable lithium-sulfur battery. J Power Sources 26:269-271

2. Manthiram A, Fu Y, Su YS (2013) Challenges and Prospects of Lithium-Sulfur Batteries. Acc Chem. Res 46:1125-1134

3. Evers S, Nazar LF (2013) New Approaches for High Energy Density Lithium-Sulfur Battery Cathodes. Acc Chem Res 46: 1135-1143

4. Mikhaylik YV, Akridge JR (2004) Polysulfide Shuttle Study in the Li/S Battery System. J Electrochem Soc 151:A1969-A1976

5. Ji X, Nazar LF (2010) Advances in Li-S batteries. J Mater Chem 20:9821-9826
6. Chen SR, Zhai YP, Xu GL, Jiang YX, Zhao DY, Li JT, Huang L, Sun SG (2011) Ordered mesoporous carbon/sulfur nanocomposite of high performances as cathode for lithium-sulfur battery. Electrochim Acta 56:9549-9555

7. Dorfler S, Hagen M, Althues H, Tubke J, Kaskel S, Hoffmann M (2010) High capacity vertical aligned carbon nanotube/sulfur composite cathodes for ithium-sulfur batteries. Chem Commun 48: 4097-4099

8. Guo J, Xu Y, Wang C (2011) Sulfur-Impregnated Disordered Carbon Nanotubes Cathode for Lithium-Sulfur Batteries. Nano Lett 11:4288-4294

9. Elazari R, Salitra G, Garsuch A, Panchenko A, Aurbach D (2011) Sulfur-impregnated activated carbon fiber cloth as a binder-free cathode for rechargeable Li-S batteries. Adv Mater 23:5641-5644

10. Wang JZ, Lu L, Choucair M, Stride JA, Xu X, Liu HK (2011) Sulfur-graphene composite for rechargeable lithium batteries. J Power Sources 196:7030-7034

11. Wang H, Yang Y, Liang Y, Robinson JT, Li Y, Jackson A, Cui Y, Dai H (2011) Graphene-Wrapped Sulfur Particles as a Rechargeable Lithium-Sulfur Battery Cathode Material with High Capacity and Cycling Stability. Nano Lett 11:2644-2647

12. Swiderska-Mocek A, Rudnicka E (2015) Lithium Sulphur battery with activated carbon cloth sulphur cathode and ionic liquid electrolyte. J Power Sources 273:162-167

13. Zhang SS (2013) Liquid electrolyte lithium/sulfur battery: fundamental chemistry, problems and solutions. J Power Sources 231: $153-162$

14. Scheers J, Fantini S, Johasson P (2014) A review of electrolytes for lithium-sulfur batteries. J Power Sources 255:204-218

15. Seh ZW, Sun Y, Zhang Q, Cui Y (2016) Designing high-energy lithium-sulfur batteries. Chem Soc Rev 45:5605-5634

16. Aftekhari A, Kim DW (2017) Cathode materials for lithium-sulfur batteries: a practical perspective. J Mater Chem A 5:17734-17776

17. Zhang X, Xie H, Kim CS, Zaghib K, Mauger A, Julien CM (2017) Advances in lithium sulfur batteries. Mater Sci Eng R 121:1-29

18. Kumar R, Liu J, Hwang JY, Sun YK (2018) Recent research trends in Li-S batteries. J Mater Chem A 6:11582-11605

19. Zhang L, Wang Y, Niu Z, Chen J (2019) Advanced nanostructured carbon-based materials for rechargeable lithium-sulfur batteries. Carbon 141:400-416 
20. Zhu J, Zhu P, Yan C, Dong X, Zhang X (2019) Recent progress in polymer materials for advanced lithium-sulfur batteries. Prog Polym Sci 90:118-163

21. Yuan X, Feng JK, Ai XP, Cao YL, Chen SL, Yang HX (2006) Improved dischargeability and reversibility of sulfur cathode in a novel ionic liquid electrolyte. Electrochem Commun 8:610-614

22. Cheon SE, Ko KS, Cho JH, Kim SW, Chin EY, Kim HT (2003) Rechargeable Lithium Sulfur Battery I. Structural Change of Sulfur Cathode During Discharge and Charge. J Electrochem Soc 150: A796-A799

23. Yamin H, Gorenshtein A, Penciner J, Sternberg Y, Peled E (1988) Lithium Sulfur Battery Oxidation/Reduction Mechanisms of Polysulfides in THF Solutions. J Electrochem Soc 135:1045-1048

24. Chen H, Shen Y, Wang C, Hu C, Lu W, Wu X, Chen L (2018) Review - From Nano Size Effect to In Situ Wrapping: Rational Design of Cathode Structure for High Performance Lithium -Sulfur Batteries. J Electrochem Soc 165:A6034-A6042

25. Fan X, Sun W, Meng F, Xing A, Liu J (2018) Advanced chemical strategies for lithium-sulfur batteries: A review. Green En \& Envir $3: 2-9$
26. Fang R, Zhao S, Sun Z, Wang DW, Cheng HM, Li F (2017) More Reliable Lithium-Sulfur Batteries: Status, Solutions and Prospects. Adv Mater 29:1606823

27. Yan B, Li X, Bai Z, Song X, Xiong D, Zhao M, Li D, Lu S (2017) A review of atomic layer deposition providing high performance lithium sulfur batteries. J Power Sources 338:34-48

28. Mentbayeva A, Belgibayeva A, Umirov N, Zhang Y, Taniguchi I, Kurmanbayeva I, Bakenov Z (2016) High performance freestanding composite cathode for lithium-sulfur batteries. Electrochim Acta 217:242-248

29. Li Z, Wua HB, Lou XW (2016) Rational designs and engineering of hollow micro/nanostructures as sulfur hosts for advanced lithium-sulfur batteries. Energy Environ Sci 9:3061-3070

Publisher's note Springer Nature remains neutral with regard to jurisdictional claims in published maps and institutional affiliations. 